DOI https://doi.org/10.30525/2592-8813-2021-1-5

\author{
Karina Ostapenko
}

\title{
INTERGENERATIONAL TRANSMISSION OF VALUES
}

\begin{abstract}
The need in mature, scientifically ground state migration policy is extremely high, and it is becoming more and more pressing with each subsequent year. There is an increasing demand for crosscultural comparisons, as far as yet more ethnic groups are becoming involved into migration processes. The research applied the conceptual approach, covering representatives of three generations of one and the same family. The research has demonstrated that four types of acculturation statements correspond to certain types of behavior in the process of acculturation, types of ethnic and civic identity formation. It has also revealed essential correlations of ethnic identity with acculturation strategies in three generations.
\end{abstract}

Key words: cultural tramsmission, generational, transmission of values.

\section{Approaches and basic definitions to the study of the transmission of values}

Transmission of values from parent to teen-ager is often seen as a sign of successful socialization, which includes "the voluntary acceptance of values, standards and customs for adaptive operation in a larger social context" [Grusec \& Davidov, 2007]. Adolescence is a very important phase in the study of the value transmission, because it is a time of identity development, which is characterized by the tension between increased need for autonomy and increased conformity to the social expectations, the conformity is necessary for the acquisition of appropriate models of behavior. Thus, during adolescence children become highly suspectible to the messages conveying values, more than in any other period of childhood (Padilla-Walker 2007).

Value transfer is defined as an interactive process. It is assumed that parents and children have the innate abilities to start action, understanding their interactions with each other and making choices (Kuczynski, Navara 2006; Roest et al. 2010).

Because the transmission is interactive, it may be the reason of both: intergenerational change and the similarities between generations, however, change is not necessarily a mistake, but a possible outcome. The transmission of values from one generation to another without any changes is not always desirable, because, perhaps, new generations will have to adapt to modified living conditions, consequently, a complete transmission without any changes would be disadvantageous for an individual as well as a complete lack of transmission. Both cases would be unfavorable for successful socialization (Scholnpflug 2001; Trommsdoff 2009.

Cultural transmission is the process by which culture is transmitted from previous generations to the next generations through learning. Cultural transmission creates such a phenomenon as the succession of culture, its continuity in time.

A consistent change of the cycles of cultural development within the framework of one nation or country should be as follows: previous generation should transmit the basic elements of culture to the next generation, however, secondary or non-essential values should be modified. Succession is ensured by direct contact of cultural carriers acting as teachers and students.

Since any culture develops over time, a significant part of the past cultural heritage, which has proven its value, is preserved at a new stage. The breaking of the cultural chain occurs when the lifestyle of people - carriers of a given culture - suddenly changes.

(C) Karina Ostapenko,

Mg.psych., doctoral student (Latvia, Daugavpils University) 
Currently, ethnopsychology uses another concept - cultural transmission, which includes the processes of enculturation and socialization and is a mechanism by which an ethnic group "inherits itself" to its new members, first of all children (Berry et al., 1992). While using cultural transmission, a group can perpetuate their specificities in the next generations through basic learning mechanisms. There are usually three types of transmission:

- vertical transmission, during which cultural values, skills, beliefs, etc., are transferred from parents to children;

- horizontal transmission, is the period from birth to adulthood, when a child learns social experience and cultural traditions, during communication with peers;

- "indirect" (oblique) transmission, when individual study in specialized institutions of socialization (schools, universities), as well as has a practice, learning from adults around him (relatives, senior community members, neighbors, etc.).

Cultural transmission is important for succession in a society, as it maintains communication between members of different generations and allows to preserve the cultury-specific knowledge and beliefs between generations. Intergenerational transmission of the focuses is a kind of social learning, socialization, by which, children when become adults can continue to adhere to certain norms, rules, etc., moreover, transfer these focuses to the next generation - this is the continuity and succession of culture. Parents are usually concerned about the succession of values, however, children try to become independent from their parents (Lebedeva, Latypova).

Differences between generations may be caused by the choices that parents make about what values they will transffer and the choices children make about accepting or rejecting those values. This was clearly shown in the Grusec and Goodnow's model of value acquisition (Grusec and Goodnow's model 1994).

Grusec and Goodnow (1994) have proposed two groups of variables that are relevant to child acceptance of the values, according to their effect on: (a) child motivation and (b) the degree to which children see values as self-generated. The first group relates to the degree to which children are motivated to accept parents' values: harmony between parents, warmth and closeness between parents and their children are important factors. More generally, the positive relationships (few conflicts and high levels of closeness) should increase children's willingness to agree with their parents' wishes, as this promotes children's desire to identify with their parents and children's desire to obey. The second group concerns such variables as minimizing threats of autonomy, which can lead to a children belief that values are self-generated. The intrinsic motivation would lead to a higher level of children openness to parents' messages and their acceptance, since the messages would not be perceived as a threat to the autonomy. In this sense, children are able to satisfy two important needs: conformity in relation to the other's expectations and autonomy.

Thus, modest acceptance of values can have different roots and, as a result, different routes of intervention. Creating a balance in a relationships of a married couple and in a parent-child relationship (in which parents and children are neither too close nor distant) should be the main goal of any intervention aimed at improving the transmission of values in the family and the moral development of teen-agers. Parents and teachers can contribute to a teen's moral development by enhancing positive relationships and encouraging teen-ager's independence (Kuczynski, Hildebrandt 1997).

Parents should explain the importance and significance of the transmitted values so the child can fully understand their importance and learn these values as his own, thereby feeling independence following them (Hardy et al. 2008). The growing independence of the teen-ager is the most important factor of the psychosocial adaptation associated with a number of desirable educational outcomes (Grolnick et al. 1991; Soenens et al. 2007). In educational institutions, students who feel their autonomy being supported tend to be more autonomous during study process and tend to integrate the material. 
To achieve a high level of coherence between parent and child values, the child's desire to accept values is not enough; it is also necessary for child to accurately perceive the values that parents want to convey (Grusec and Goodnow's).

Teen-agers think that parents strive to maintain in them primarily conservative values, while they are more open to new experience and challenges. Due to that reason, teen-agers refuse to accept conservative values.

Teen-agers explore and develop their autonomy and independent identity. The values of openness to changes that promote independence are most effective in that motivation. On the other hand, at this stage of the life cycle, parents must take care of their children. Parents need to take into account the dependency aspects, child's need for safety and rules that continue existing throughout adolescence, as well as the adolescent's growing need for autonomy (Scabini et al. 2006). From this point of view, the opposite patterns of perception of values (adolescents who consider themselves as conservative, and their parents striving for pleasure and searching for novelty) or the complete match of the values of parents and children ("I am absolutely the same as my father/my mother wants to see me") would be unexpected and would also contradict transmission problems in families (Barni 2009).

\section{Schwartz's value model}

In his individual approach, Schwartz argues that the main aspect that separates values from each other is the type of motivation in which they are reflected (Schwartz 1999-2006). Therefore, he grouped individual values into value complexes (types of motivation) that share a common goal. He argued that the basic human values that should be in all cultures are those that represent universal human needs (biological needs, the needs of coherent social interaction and the requirements for life in a group). Based on the values mentioned by previous researchers and religious, and philosophical works in different cultures, he grouped values into 10 different types of human motivation, which he understood as the main types or blocks of values (10 types were identified). These determine the focus of the individual's specific actions and all his life activity. Each type of motivation has its leading motivational goal:

Self-direction. The motivational goal is freedom of thought and action (choice, creativity, knowledge), conditioned by the individual's need to be autonomous and independent.

Stimulation - wealth of life. The motivational goal is novelty and competitiveness in life, which is necessary to maintain an optimal level of activity in the organism.

Hedonism. The motivational goal is pleasure, enjoyment of life. It is based on the need to satisfy biological needs and the pleasure experienced during that moment.

Achievement. The motivational goal is to achieve personal success within the framework of shared cultural standards and gain social approval.

Power. The motivational goal is to achieve social status, prestige and influence on other people. Based on the need for domination, leadership.

Security. The motivational goal is stability, safety and harmony of society, family and the individual himself. It is based on the need for adaptability and predictability of the world, reduction of uncertainty.

Conformity. A motivational goal is to restrict actions and motives that harm others or violate social harmony. It is based on the need of groups for self-preservation and survival and the need of the individual to harmonically interact with other people, while suppressing socially destructive obliquities.

Tradition. The motivational goal is to respect and uphold customs, acceptance of the ideas that exist in a particular culture and religion. Traditional behavior becomes a symbol of the group's solidarity, an expression of the uniqueness of its picture of the world.

Benevolence. The motivational goal is to maintain and increase the well-being of the people with whom the person is in contact. It is based on the need for positive interaction for the well-being of the group and the individual need for affiliation. 
Universalism. The motivational goal is understanding, gratitude, tolerance and maintenance of the well-being of all people and nature. This motivational type was not deduced from the three specified universal human needs, but was discovered empirically during the study of values. This goal seems to be based on the universal needs for beauty, harmony and justice.

Schwartz developed a theory of relationships between these leading types of human motivation (Schwartz, Bilsky 1990). The logic of the relationship between values is deduced by the relationship between the motives of behavior and the actions. Each type of motivation has a goal that guides a person's aspirations, which lead to concerted or conflicting actions. Thus, the conflict or harmony between values determines the strategies of behavior.

The authors proposed the following typology of contradictions between values.

1. The values of "Conservation" - safety, conformity, tradition - contradict the values of "openness to change" - stimulation and independence. Here there is a clear opposition between the value of the autonomy of the views, actions of the individual and the value of preserving traditions, maintaining the stability of the society.

2. The values of "Self-Transcendence" - universalism, benevolence-contradict the values of "SelfEnhancement" - power, achievement, hydonism. There is also a clear position between caring for the welfare of others and the desire to dominate people.

\section{Previous researches}

Previous studies have provided evidence of intergenerational transmission of values in both individualistic and collectivist cultures (Boehnke 2001; Georgas 1991; Knafo, Schwartz 2001, 2003; Phale, Scholnpflug 2001; Pinquart, Sillbereisen 2004).

The values that parents would like to see in their children the most, in the literature are reffered as "socialization values" are not necessarily identical with the personal values of the parents. Although some studies (for example, Knafo, Schwartz 2001) have shown a strong correlation between the values parents want to have for themselves and the values they want their children to have (Pearson's correlation coefficient from 60 to .80), there was no perfect agreement. Thus, the measured agreement between the values of parental socialization and the personal values of the children, not between the personal values of the parents and the personal values of the children reflects the favorable outcome of the presumptive socialization.

A number of studies have looked at factors that may influence the accuracy with which children perceive parents' values. Drawing the child's attention, clarity and abundance of parents' messages are positively associated with accuracy (Okagaki, Bevis 1999; Knafo, Schwartz 2003).

As previous studies (Barni, Ranieri 2010) show, we can assume that the values of parents and teen-agers become more homogeneous by the time of age of majority. The progressive attribution of adult roles by children and increasing responsibility also mean acceptance of parent-shared priorities and beliefs, consistent with personal and social life and the adult generation as a whole. Some authors (Vollebergh et al. 2001) consider late adolescence as a "stage of formation", the foundation of deeper moral and cultural orientations.

The adolescents' perception of parents' harmony in relationships was found to be more significant than the actual degree of parents' harmony in relationships in determining the level of acceptance. This confirms the central role of perception in interpersonal processes and its role as a filter of reality (Gagné, Lydon 2004), supporting the importance of relying on individual perception. A number of studies in recent decades have been based on adolescents' personal reports of parent-child relationships, which have been considered as meaningful sources for understanding family processes. The choice to use the views of adolescents was based on the belief that adolescents can give an accurate picture of family relationships, regardless of whether adolescents may be accurate or not, their perception of family processes determines their choices and behavior (Smetana et al. 2002). This seems to hold true for the acceptance stage in the value transmission process. 
The family context, characterized by closeness and support, encourages the child to accept parents' values as it increases desire to please the parents. In addition, family closeness is usually characterized by the presence of interests, values and behaviors shared by all family members (Scabini et al. 2006).

Grusec and Goodnow introduced the concept of "self-generation", which means that the child should feel that he is creating his own values and that this feeling promotes acceptance the values.

For the first time in Latvia, the study "Transmission of values in three generations in Latvian families" was carried out in 2014 (Plotka, Blumenau, Čače 2014). The study showed that the older generation (mothers and grandmothers) is dominated by social values, while the younger generation is dominated by individual values. For young people, such values as self-realization, openness to changes are important, which indicates the personal orientation of the value orientation.

\section{Conclusion}

Research on the transmission of values makes it possible to identify both stable and variable elements of culture, a range of changes in values and social attitudes, which is important not only for science, but also for the practice of interpersonal and intercultural interaction.

\section{References}

Albert I., Trommsdorff G., Wisnubrata L. (2009). Intergenerational transmission of values in different cultural contexts: A study in Germany and Indonesia. - Quod Erat Demonstrandum: From Herodotus' ethnographic journeys to cross-cultural research. Pp. 221- 230.

Aron A., Aron E. N., Smollan D. (1992) Inclusion of other in the self scale and the structure of interpersonal closeness. - Journal of Personality and Social Psychology. pp. 596-612.

Barni D. (2009) Transmitting values. A comparison between three family generations. Milano: Unicopli.

Barni D., Ranieri S. (2010) Value transmission in the family: a dyadic measure of parent-child value similarity. - C. Galimberti, G. Scaratti (eds.) Epistemologies of complexity in psychological research. pp. 63-95.

Baron R. M., Kenny D. A. (1986) The moderator-mediator variable distinction in social psychological research: conceptual, strategic and statistical considerations. - Journal of Personality and Social Psychology. pp. 1173-1182.

Boehnke K., Hadjar A., Baiter D. (2007) Parent-Child Value Similarity: The Role of Zeitgeist. - Journal of Marriage and Family. pp. 778-792. https://onlinelibrary.wiley.com/ doi/10.1111/j.1741-3737.2007.00405.x

Knafo A., Schwartz S. H. (2001) Value socialization in families of Israeli-born and Soviet-born adolescents in Israel.- Journal of Cross-Cultural Psychology. No 32 (2). pp. 213-228.

Knafo A., Schwartz S. H. (2003) Parenting and adolescents' accuracy in perceiving parental values. Child Development. No 74 (2). pp. 595-611.

Lebedeva N. M. Tatarko A. N. (2011). Methods of ethnic and cross-cultural psychology. Moscow: HSE. [Лебедева Н. М. Татарко А. Н. (2011). Методы этнической и кросскультурной психологии. Москва: НИУ ВШЭ] 
Schwartz Sh., Butenko T. P., Sedova D. S.,. Lipatova A. S (2012) A refined theory of basic individual values: application in Russia. - Psychology. Journal of the Higher School of Economics. Vol. 9, No. 1. pp. 43-70. [Шварц Ш., Бутенко Т. П., Седова Д.С., Липатова А. С. (2012) Уточненная теория базовых индивидуалних ценностей: применение в Росии. - Психология. Журнал Высшей школы экономики. Т. 9, № 1. с. 43-70] 